\title{
Frequency of Cardiovascular Manifestation in Patients With Hyperthyroidism
}

\author{
Naresh Kumar Khurana ${ }^{1}$, Suresh Kumar ${ }^{2}$, Sameet Kumar ${ }^{3}$, Pardeep Kumar ${ }^{4}$, Amber Rizwan ${ }^{5}$ \\ 1. Cardiology, Central Park Medical College, Lahore, PAK 2. Internal Medicine, Bolan University of Medical \& Health \\ Sciences, Quetta, PAK 3. Internal Medicine, Chandka Medical College, Karachi, PAK 4. Medicine, Jinnah Sindh Medical \\ University, Karachi, PAK 5. Family Medicine, Jinnah Post Graduate Medical Center, Karachi, PAK
}

Corresponding author: Amber Rizwan, amber_aljazeera109@hotmail.com

\section{Abstract}

\section{Introduction}

Cardiovascular manifestations are very common in hyperthyroidism. Various cardiovascular symptoms such as palpitations, exercise intolerance, dyspnea, angina, edema, and congestive heart failure are commonly reported in hyperthyroidism. In this study, we determine the frequency of cardiovascular signs, symptoms, and various conduction disorders associated with hyperthyroidism.

\section{Methodology}

This cross-sectional, observational study was conducted in the cardiology department of a tertiary care hospital in Pakistan in close association with the internal medicine department from August 2019 to December 2019. A total of 100 hyperthyroid patients confirmed based on thyroid stimulating hormone (TSH, also known as thyrotropin), free $\mathrm{T}_{4}$ ( $\mathrm{FT}_{4}$; thyroxine), and free $\mathrm{T}_{3}\left(\mathrm{FT}_{3}\right.$; triiodothyronine) were enrolled in the study.

\section{Results}

The most common cardiovascular symptom in this study was palpitations identified in $72 \%$ of the participants, followed by breathlessness in $41 \%$ of the participants. The most common cardiovascular sign was a pulse rate of more than 100 beats per minute found in $72 \%$ of the participants. The most common abnormality in electrocardiogram (ECG) was sinus tachycardia in $39 \%$ of the participants, followed by atrial fibrillation in $22 \%$ of the participants. In echocardiography, $5 \%$ of the participants had systolic dysfunction.

\section{Conclusion}

In this study, cardiovascular signs, symptoms, ECG, and echo changes were very frequent in hyperthyroidism. Management of hyperthyroidism should include routine ECG and echo testing, and cardiologists should be involved in thorough cardiovascular examination.

Review began 01/11/2021 Review ended 01/18/2021 Published 01/21/2021

\section{(๑) Copyright 2021}

Khurana et al. This is an open access article distributed under the terms of the Creative Commons Attribution License CC-BY 4.0., which permits unrestricted use, distribution, and reproduction in any medium, provided the original author and source are credited.
Categories: Cardiology, Endocrinology/Diabetes/Metabolism, Internal Medicine

Keywords: hyperthyroidism, cardiovascular symptoms

\section{Introduction}

Hyperthyroidism is defined as excess concentration of thyroid hormones in the body due to either increased synthesis of the thyroid hormone, increased release of preformed thyroid hormones, or from endogenous or exogenous extrathyroidal sources [1]. Hyperthyroidism is very prevalent worldwide. According to a 2002 study, Pakistan reported a prevalence of 5.1\% for hyperthyroidism and 5.8\% for clinical hyperthyroidism [2].

Clinical symptoms of hyperthyroidism depend upon various factors including patient's age, sex, presence of other diseases, duration of the disease, and cause of the disease. Older patients exhibit fewer and less severe symptoms but may end up with more cardiovascular complications [3-5]. Various cardiovascular symptoms such as palpitations, exercise intolerance, dyspnea, angina, edema, and congestive heart failure are commonly present in patients with hyperthyroidism [6,7]. Atrial fibrillation is reported in $10-25 \%$ of hyperthyroid patients and may cause further complications [8].

Despite hyperthyroidism being very prevalent in Pakistan, there is very limited data available in Pakistan, particularly related to cardiovascular symptoms and complications. In this study, we determine the frequency of cardiovascular signs, symptoms, conduction disorders, and arrhythmias in hyperthyroidism.

\section{Materials And Methods}

This cross-sectional, observational study was conducted in the cardiology department of a tertiary care 


\section{Cureus}

hospital in Pakistan in close association with the internal medicine department from August 2019 to December 2019. Ethical review board approval was taken from the Bolan University of Medical Health Sciences before the start of the study. A total of 100 patients under treatment of hyperthyroid confirmed based on thyroid stimulating hormone (TSH, also known as thyrotropin), free $\mathrm{T}_{4}$ ( $\mathrm{FT}_{4}$; thyroxine) and free $\mathrm{T}_{3}$ ( $\mathrm{FT}_{3}$; triiodothyronine) were enrolled in the study. Patients with hypertension, diabetes mellitus, congestive heart failure, and coronary artery disease were excluded from study.

After obtaining informed consent, patient history was taken for cardiovascular symptoms such as palpitations, breathlessness, chest pain, and edema. Patient pulse and standing blood pressure were recorded via digital instruments. Cardiovascular auscultation was done to identify any abnormal heart sound. Chest X-ray (cardiothoracic ratio above 0.5 ) was done to identify cardiomegaly. Electrocardiogram (ECG) and echocardiography was done to identify various abnormalities.

Statistical analysis was done using the Statistical Package of Social Sciences (SPSS) version 21.0 (IBM Corporation, Armonk, New York, USA). Continuous variables were presented as means and standard deviations, while categorical variables were presented as percentages and frequencies.

\section{Results}

The mean age of the participants was $39 \pm 12$ years. There were 21 (21\%) males and 79 (79\%) females in the study. The mean duration of diagnosis of hyperthyroidism was $4 \pm 2$ years. Mean TSH level was $0.091 \pm 0.09$ $\mathrm{mU} / \mathrm{L}$. Mean $\mathrm{FT}_{4}$ was $2.22 \pm 0.31 \mathrm{ng} / \mathrm{dL}$. Mean $\mathrm{FT}_{3}$ was $4.51 \pm 0.25 \mathrm{ng} / \mathrm{dL}$.

The most common symptom in this study was palpitations (72\%), followed by breathlessness (41\%). The most common sign was tachycardia (pulse rate of more than 100 beats per minute) identified in $72 \%$ of the participants (Table 1).

\begin{tabular}{|l|l|}
\hline Signs and symptoms & Percentage \\
\hline Edema (\%) & 14 \\
\hline Palpitations (\%) & 72 \\
\hline Breathlessness (\%) & 41 \\
\hline Chest pain (\%) & 06 \\
\hline Number of participants with systolic blood pressure greater than $130 \mathrm{mmHg}(\%)$ & 41 \\
\hline Number of participants with diastolic blood pressure greater than $80 \mathrm{mmHg}(\%)$ & 07 \\
\hline Number of participants with pulse rate greater than 100 beats per minute (\%) & 72 \\
\hline Loud pulmonary (P2) sound & 21 \\
\hline Other sounds & \\
\hline
\end{tabular}

TABLE 1: Cardiovascular signs and symptoms in hyperthyroid patients.

In chest X-ray, cardiomegaly was present in $10 \%$ of the participants. The most common finding in ECG was sinus tachycardia (39\%), followed by atrial fibrillation (22\%). In echocardiography, $5 \%$ of the participants had systolic dysfunction (Table 2). 


\section{Cureus}

\begin{tabular}{|l|l|}
\hline Diagnostic findings & Percentage \\
\hline Chest X-ray findings & 10 \\
Cardiomegaly & \\
ECG findings & 39 \\
Sinus tachycardia & 22 \\
Atrial fibrillation & 04 \\
Right bundle branch block & 04 \\
Left bundle branch block & 06 \\
Right ventricular hypertrophy & 06 \\
Left ventricular hypertrophy & 02 \\
Supraventricular tachycardia & 02 \\
\hline Echocardiography findings & 05 \\
\hline Systolic dysfunction & 01 \\
\hline Diastolic dysfunction & 08 \\
Regurgitant lesions & 02 \\
Pulmonary hypertension & \\
\hline
\end{tabular}

\section{TABLE 2: Cardiovascular diagnostic findings in hyperthyroid patients.}

\section{Discussion}

Various direct and indirect mechanisms are responsible for the influence of thyroid hormone on the heart and cardiovascular system [9]. Thyroid hormones influences myocytes by upregulating alpha $(\alpha)$-chain, but downregulates beta $(\beta)$-chain [10]. It may also influence sarco/endoplasmic reticulum, which may increase the rate of calcium uptake during diastole [11,12]. Thyroid hormone also directly acts on ion channels such as $\mathrm{Na} / \mathrm{K}$-ATPase, $\mathrm{Na} / \mathrm{Ca}++$ exchanger, and some voltage-gated $\mathrm{K}$ channels, hence affecting myocardial and vascular functions $[13,14]$. Other than the cellular impact of thyroid hormone, it also influences the hemodynamic balance in the body by its direct effects on the heart and blood vessels [13]. Thyroid hormones may cause rapid use of oxygen by the body, increased production of metabolic products, and relaxation of arterial smooth muscle, which may lead to peripheral vasodilation [13].

Cardiac symptoms seen in hyperthyroidism either may be due to the effect of increased sympathoadrenal activity or due to the direct effect of thyroid hormones on the heart [15]. In this study, the most common cardiac symptoms were palpitation, followed by breathlessness. Kandan et al. reported in their study that the most common cardiovascular manifestation was palpitation (78\%), followed by dyspnea/breathlessness (26\%) and chest pain (4\%) [16]. In this study, tachycardia (pulse rate greater than 100 beats per minute) was found in $72 \%$ of the participants, which was comparable to the studies of Kandan et al. and Zargar et al. $[16,17]$.

In our study, atrial fibrillation was seen in $22 \%$ of the participants, which was comparable to the study conducted by Kandan et al., which reported $28 \%$ prevalence of atrial fibrillation [16]. However, the prevalence in our study was much higher than that reported by a Saudi study conducted by Zargar et al., which reported a prevalence of $8.9 \%$ [17]. Low serum TSH is an independent risk factor for development of atrial fibrillation [18]. Atrial fibrillation has been proven to cause more mortality and morbidity due to embolic events in patients with hyperthyroidism [19]. ECG findings such as P-maximum and P-wave dispersion are important identifiers of paroxysmal atrial fibrillation [20]. In this study, systolic dysfunction was seen in $5 \%$ of the participants, which was comparable to that reported by Mercé et al. (3\%) [21]. Kandan et al. reported much higher prevalence (18\%) of systolic dysfunction in their study [16].

To the best of our knowledge, this is the first local study to identify cardiovascular manifestation in hyperthyroid patients. The study has its limitations as well. As all the participants were from one institute, the sample size was limited and less diverse. In addition, as it was cross-sectional study, long-term impact of 


\section{Conclusions}

In this study, cardiovascular manifestations such as tachycardia, breathlessness, and atrial fibrillation were very prevalent in patients with hyperthyroidism. It is important to identify cardiovascular manifestations early in patients and manage them appropriately to reduce mortality and morbidity risk. Cardiologists should be involved in the management of hyperthyroidism.

\section{Additional Information \\ Disclosures}

Human subjects: Consent was obtained or waived by all participants in this study. Bolan University of Medical Health Sciences issued approval BUMHS/IRB-Off/2019-08/12. Animal subjects: All authors have confirmed that this study did not involve animal subjects or tissue. Conflicts of interest: In compliance with the ICMJE uniform disclosure form, all authors declare the following: Payment/services info: All authors have declared that no financial support was received from any organization for the submitted work. Financial relationships: All authors have declared that they have no financial relationships at present or within the previous three years with any organizations that might have an interest in the submitted work. Other relationships: All authors have declared that there are no other relationships or activities that could appear to have influenced the submitted work.

\section{References}

1. Kravets I: Hyperthyroidism: diagnosis and treatment. Am Fam Physician. 2016, 93:363-70.

2. Khan A, Muzaffar Khan MMA, Akhtar S: Thyroid disorders, etiology and prevalence. J Med Sci. 2002, 2:8994. 10.3923/jms.2002.89.94

3. Goichot B, Caron P, Landron F, Bouée S: Clinical presentation of hyperthyroidism in a large representative sample of outpatients in France: relationships with age, aetiology and hormonal parameters. Clin Endocrinol. 2015, 84:445-51. 10.1111/cen.12816

4. Devereaux D, Tewelde SZ: Hyperthyroidism and thyrotoxicosis. Emerg Med Clin North Am. 2014, 32:277-92. 10.1016/j.emc.2013.12.001

5. Boelaert K, Torlinska B, Holder RL, Franklyn JA: Older subjects with hyperthyroidism present with a paucity of symptoms and signs: a large cross-sectional study. J Clin Endocrinol Metab. 2010, 95:2715-26. 10.1210/jc.2009-2495

6. Ghandour A, Reust C: Hyperthyroidism: a stepwise approach to treatment. J Fam Pract. 2011, 60:388-95.

7. Palitzsch KD: Prevention and multimodal therapy of hyperthyroidism [Article in German] . Internist. 2008, 49:1428-36. 10.1007/s00108-008-2155-3

8. Petersen P, Hansen JM: Stroke in thyrotoxicosis with atrial fibrillation . Stroke. 1988, 19:15-8. 10.1161/01.str.19.1.15

9. Ertek S, Cicero AF: Hyperthyroidism and cardiovascular complications: a narrative review on the basis of pathophysiology. Arch Med Sci. 2013, 9:944-52. 10.5114/aoms.2013.38685

10. Ojamaa K, Klemperer JD, MacGlivray SS, Klein I, Samarel A: Thyroid hormone and hemodynamic regulation of beta-myosin heavy chain promoter in the heart. Endocrinology. 1996, 137:802-8. 10.1210/endo.137.3.8603588

11. Dillman WH: Biochemical basis of thyroid hormone action in the heart . Am J Med. 1990, 88:626-30. 10.1016/0002-9343(90)90530-q

12. Kiss E, Jakab G, Kranias EG, Edes I: Thyroid hormone-induced alteration in phospholamban protein expression. Regulatory effects on sarcoplasmic reticulum $\mathrm{Ca} 2+$ transport and myocardial relaxation. Circ Res. 1994, 75:245-51. 10.1161/01.res.75.2.245

13. Panagoulis C, Halapas A, Chariatis E, Driva P, Matsakas E: Hyperthyroidism and the heart. Hellenic J Cardiol. 2008, 49:169-75

14. Kasturi S, Ismail-Beigi F: Effect of thyroid hormone on the distribution and activity of Na, K-ATPase in ventricular myocardium. Arch Biochem Biophys. 2008, 475:121-7. 10.1016/j.abb.2008.04.019

15. Toft P, Bøtker HE: Hyperthyroidism and heart disease. Is thyrotoxic cardiomyopathy a disease entity? [Article in Danish]. Ugeskr Laeger. 1993, 55:1354-7.

16. Kandan V, Sathyamurthy P, Rajkumar M, Narayanan L: Cardiovascular manifestation in hyperthyroidism. J Res Med Sci. 2017, 4:3032-8. 10.18203/2320-6012.ijrms20161999

17. Zargar AH, Bashir MI, Wani AI, Laway BA, Masoodi SR, Ganie MA, Salahuddin M: Clinical and endocrine aspects of thyrotoxicosis and its cardiovascular complications. Ann Saudi Med. 2000, 20:485-7. 10.5144/0256-4947.2000.485

18. Forfar JC, Miller HC, Toft AD: Occult thyrotoxicosis: a reversible cause of "idiopathic" atrial fibrillation . Am J Cardiol. 1979, 44:9-12. 10.1016/0002-9149(79)90243-1

19. Staffurth JS, Gibberd MC, Fui SN: Arterial embolism in thyrotoxicosis with atrial fibrillation . Br Med J. 1977, 2:688-90.10.1136/bmj.2.6088.688

20. Aras D, Maden O, Ozdemir O, et al.: Simple electrocardiographic markers for the prediction of paroxysmal atrial fibrillation in hyperthyroidism. Int J Cardiol. 2005, 99:59-64. 10.1016/j.ijcard.2003.11.040

21. Mercé J, Ferrás S, Oltra C, et al.: Cardiovascular abnormalities in hyperthyroidism: a prospective doppler echocardiographic study. Am J Med. 2005, 118:126-31. 10.1016/j.amjmed.2004.08.018 